\title{
COMUNICAÇÕES
}

\section{Wheat fusarium head blight 2001 epidemic in the southern Argentinian pampas}

\author{
Marcelo Carranza, Gladys Lori \& Marina Sisterna
}

Centro de Investigaciones de Fitopatología (CIDEFI), Facultad de Ciencias Agrarias y Forestales, UNLP. 60 y 119, (1900) La Plata. E-mail: fitopato@ceres.agro.unlp. edu.ar. Comisión de Investigaciones Científicas de la Prov. de Buenos Aires (CIC), Argentina Autor para correspondência: Marcelo Carraza

Data de chegada:29/03/2005. Aceito para publicação em:06/11/2007

Wheat Head Blight or Scab is frequently a destructive fungal disease caused by several Fusarium species but $F$. graminearum Schwabe [teleomorph Gibberella zeae (Schwein) Petch; synonym = G. saubinetii (Mont.) Sacc.] is the principal causal agent. The disease is common in humid and semi-humid wheat (Triticum spp.) cropping areas around the world.

Epidemics of Fusarium head blight (FHB) seem to be increasing globally during the last two decades. In Argentina and some other countries of South America, damages have been very significant. In the USA, Canada and other wheat cropping areas, several harvests have been affected by numerous epidemics.

FHB is not only of concern for its effect on the grain that is used for food or feed, but also for the grain that is used for seed. Wheat head attacked by $F$. graminearum produces seed that are affected in size, quality, color and quantity. Yield loss results when primary infection of spikelets by ascospores is followed by rachis colonization and death. In susceptible cultivars, many developing spikelets may be killed or damaged prior to grain fill. Additional loss results during mechanical harvest because seed produced in affected heads are not retained.

Infection begins when spores are windblown onto exposed anthers of wheat heads. The critical period for infection extends from the beginning till the end of flowering, the crop being less susceptible when grain filling starts. The anthers constitute an important nutritional substrate for the fungus, enhancing its rapid growth towards the ovaries and developed grains.

The first report of $F$. graminearum in Argentina was on common wheat (Triticum aestivum L.) in 1927 by Marchionatto and in the following year, the teleomorph state of the causal agent was determined by Lindquist in La Plata, Buenos Aires province.

After the first report of $F$. graminearum the disease was observed during the subsequent decades on wheat spikes causing the typical head blight symptoms. However, it took another fifteen years before the disease became widespread.

In Argentina the wheat cropping area is very extensive reaching nearly 6.000.000 ha and is distributed in five provinces with different ecological conditions (Buenos Aires, Córdoba, Santa Fe, Entre Ríos and La Pampa). Therefore, one single epidemic has never covered the whole area at the given time. Latitude, temperature and the importance of susceptible rotational crops (particularly Zea mays L.) and susceptible grass influence the pathogen's distribution, while the frequency and timing of spring rainfall appear to regulate disease outbreaks.

In the central northern region (southeastern of Córdoba, southern Santa Fe and northern Buenos Aires) the worst outbreaks occurred in 1945-46, 1967, 1977-78, 1985 and 1993, when yield losses varied among zones but were estimated to average between 20 and $30 \%$. In 1993 the highest estimated losses reached 50\% in the southern and southeastern Santa Fe and Córdoba provinces in areas of no-till over maize stubble. In the most affected areas, nearly all production traded below established standards. The extent of the damage was magnified by a considerable loss in the grain trading value resulting from low test weight, presence of scabby grain and mycotoxin contamination. Besides, samples showed deoxynivalenol concentration values ranging from 2 to $28 \mathrm{ppm}$ with an overall mean of $11.26 \mathrm{ppm}$. Only $10 \%$ of the samples complied with the Food and Drug Administration-USA and Canadian guidelines for this mycotoxin.

In the southeast wheat growing area, the main durum wheat (Triticum durum Desf.) region of southern Buenos Aires and La Pampa province, severe epidemics ocurred in 1963, 1976, 1978 and 1985, with crop losses as high as $70 \%$. In 1976, durum wheat accounted for $20 \%$ of the area with wheat production. The epidemic was too severe that $60 \%$ of samples from farms were below established standards (low weight per hectoliter, presence of scabby grains and mycotoxin contamination).

Also during 2001 early severe symptoms were observed in the southeast wheat cropping region and reports of severe FHB infections were registered in the central northern area too.

The purpose of this work was to show the FHB incidence and severity and to measure the degree seed infection in cultivars grown in four localities of Buenos Aires province during the 2001 epidemic.

Wheat seeds obtained from experimental plots carried out in four localities of Buenos Aires province: Necochea ( $38^{\circ} 10^{\prime} \mathrm{S}, 58^{\circ}$ $\left.00^{\prime} \mathrm{W}\right)$; Miramar $\left(38^{\circ} 00^{\prime} \mathrm{S}, 57^{\circ} 33^{\prime} \mathrm{W}\right)$; Balcarce $\left(37^{\circ} 45^{\prime} \mathrm{S}, 58^{\circ}\right.$ $\left.18^{\prime} \mathrm{W}\right)$ and Los Hornos $\left(35^{\circ} 25^{\prime} \mathrm{S}, 60^{\circ} 10^{\prime} \mathrm{W}\right)$ were analyzed. The total number of samples for common wheat for all the localities was 131 and 20 for durum wheat for only two sites (Necochea and Miramar).

Determination of $\mathrm{FHB}$ incidence and severity. Incidence and severity data were submitted from Seed Breeding Buck (Necochea) and Experimental Stations (Miramar, Balcarce and Los Hornos). They were evaluated at late flowering stage. The incidence was determined as the proportion of infected spikes over total plot spikes. The severity was assessed by counting the number of infected spikelets/total heads of each plot.

Determination of seed fungal invasion and seed quality. To determine the percentage (\%) of kernel infection by F. graminearum, 400 kernels per sample were subjected to the blotter test following the ISTA rules. With the aid of a stereoscopic microscope, after 7 days of incubation, fungi growing from kernels were identified and seed germination (SG) was determined. The presence of $F$. 
Table 1. Disease and quality parameters in common and durum wheat samples obtained from different localities in the Buenos Aires Province

\begin{tabular}{|c|c|c|c|c|c|c|c|c|c|c|}
\hline & \multicolumn{2}{|c|}{ Incidence $(\%)$} & \multicolumn{2}{|c|}{ Severity $(\%)$} & \multicolumn{2}{|c|}{ Fusarium contamination $(\%)$} & \multicolumn{2}{|c|}{ Seed Germination } & Thousand & Kernel Weight (\%) \\
\hline & Mean & Range & Mean & Range & Mean & Range & Mean & Range & Mean & Range \\
\hline \multicolumn{11}{|c|}{ Common wheat } \\
\hline Miramar & 39.5 & $28-62$ & 11.0 & $7-5$ & 12.7 & $5.7-27.7$ & 82.2 & $60.5-91.5$ & 29.5 & $23.8-33.4$ \\
\hline Balcarce & 42.9 & $30-61$ & 11.0 & $9-14$ & 15.7 & $8.2-24.5$ & 80.7 & $69.5-89.2$ & 28.8 & $25.4-32.7$ \\
\hline Los Hornos & 34.2 & $19-53$ & 9.6 & $6-13$ & 13.7 & $6.2-27.7$ & 82.2 & $60.2-90-5$ & 28.4 & $21.6-31.5$ \\
\hline \multicolumn{11}{|l|}{ Durum wheat } \\
\hline Necochea & 54.0 & $40-76$ & 12.8 & $11-15$ & 27.0 & $18.2-41.5$ & 66.5 & $44.2-76.2$ & 28.2 & $22.7-34.6$ \\
\hline Miramar & 64.1 & $52-76$ & 13.9 & $12-15$ & 28.5 & $24.0-35.2$ & 66.7 & $60.2-71.7$ & 29.1 & $26.8-33.2$ \\
\hline
\end{tabular}

graminearum was confirmed based on cultural features and the micromorphology on potato dextrose agar (PDA). Seeds with symptoms of wheat scab were visually identified and thousand kernel weight (TKW) was also determined.

In Argentina, epidemics are more severe in the humid pampeana region. In the southern area of the Buenos Aires province, the epidemics registered in 1963, 1976, 1977 and 1985 produced serious damage, especially in durum wheats. In the east central part (SE Córdoba province, S Santa Fe province and N of Buenos Aires province), moderate to severe outbreaks were observed in 1927, 1945, 1950, 1960, 1963, 1967, 1977, 1978, 1985 and 1993. For the last three attacks, mean incidence data were 63,50 and $75 \%$, respectively.

Our results showed, for both wheat species, that the levels of incidence and severity were high, reaching epidemic values (Table 1). There were similar data for all the localities. For common wheat, Balcarce showed the highest mean. In the case of Los Hornos, situated in a marginal cropping area, the lowest average was determined. All samples of common wheat and durum wheat were contaminated with $F$. graminearum and the infection ranged from 5.7 to $27.7 \%$ and of 18.2 and $35.2 \%$, respectively. The samples with the largest amounts of infection had the lowest test weight. The reverse was true for seed germination. Balcarce, situated in the typical wheat cropping area, showed the highest incidence values in common wheat as well as the highest percentage of $F$. graminearum contamination.

In previous reports wheat lines differed in their reaction to FHB, but no resistant cultivars are available. However, for many years, differences in susceptibility to scab among wheat cultivars have been noted, and other factors have been examined. Many of these observations were based on experimental inoculations or controlled environments. Our analyses of naturally produced seed indicate that cultivars currently grown in the southern Argentinian pampas region show little differences in susceptibility to $F$. graminearum in a year favorable to disease occurrence. None of the cultivars was free of scab at either location. Variations in the responses, apart from genetic factors, may be due to diversification on data heading, differences in the infested crop residue management, presence of gramineous and non-gramineous plants that help to maintain populations of $F$. graminearum in the field, among other factors.

Efforts directed towards the combination of desired agronomic characters with a high degree of resistance and adequate integrated disease management strategies represent an achievable goal in Argentina. 